\title{
A COOPERAÇÃO E SOLIDARIEDADE ESTIMULADAS ATRAVÉS DA EDUCAÇÃO AMBIENTAL COMO VALORES CARACTERÍSTICOS DA SUSTENTABILIDADE
}

\begin{abstract}
RESUMO
A Educação Ambiental é um importante instrumento de construção e afirmação de saberes comprometidos com as causas relacionadas à natureza, sua proteção e equilíbrio. Dessa forma delineia-se uma nova consciência social voltada para a sustentabilidade em prol de um meio ambiente equilibrado para as presentes e futuras gerações, que também necessitarão desse equilíbrio para a manutenção da vida. $\mathrm{O}$ presente trabalho atenta para o papel da referida educação como forma de estabelecer a afirmação e adoção de um desenvolvimento sustentável, reforçando certos valores necessários para a permanência da nova consciência, quais sejam a solidariedade e a cooperação.
\end{abstract}

PALAVRAS-CHAVE: Educação Ambiental; sustentabilidade; cooperação; solidariedade.

\section{INTRODUÇÃO}

Aprimorando seu conhecimento quanto às demandas ambientais, o homem deixa de ser um agente poluidor e passa a ser um colaborador na conservação da natureza. Para tanto, a educação é uma forma para capacitar a pessoa humana, criando uma convivência em harmonia com a natureza, bem como a compreensão dos limites a serem respeitados para uma utilização adequada dos bens ambientais. Assim, afastam-se os riscos de um consumo desmedido, uma vez que os recursos naturais são finitos, desenvolvendo então um indivíduo pautado por um consumo consciente de suas necessidades, responsável e solidário.

Esse contexto harmônico, decorrente de uma aprendizagem voltada para a construção de um consciente social ecológico traz consigo o comprometimento com práticas sustentáveis, e, para o desenvolvimento destas, cabe ao ser humano estar atrelado aos valores de solidariedade e cooperação.

\footnotetext{
${ }^{1}$ Especialista em Direito Público pela Escola Superior da Magistratura Federal (ESMAFE/RS); Especialista em Educação Ambiental pela Universidade Federal de Santa Maria (UFSM); Aluna especial do Mestrado em Filosofia e Graduanda em Filosofia na mesma instituição; Bacharel em Direito pelo Centro Universitário Franciscano (UNIFRA). Advogada. E-mail: laranunes7 @ hotmail.com.
} 


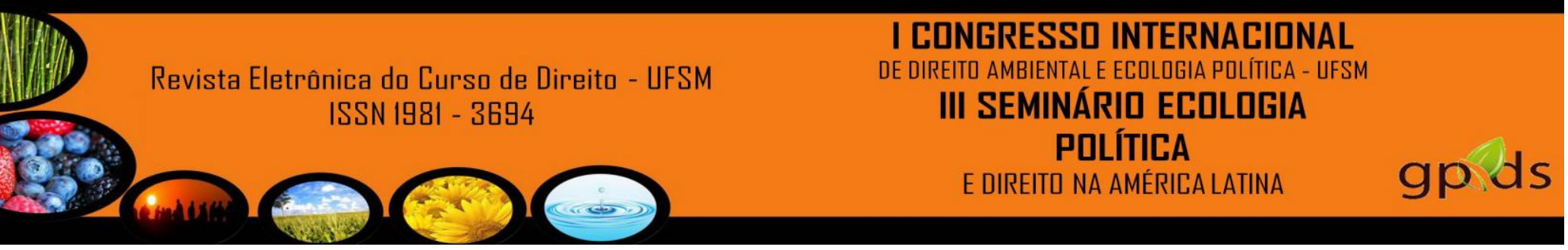

Outro momento em que se verifica o destaque para a cooperação, ocorreu na Comissão Mundial sobre Meio Ambiente e Desenvolvimento, também conhecida como ECO-92, celebrado na cidade do Rio de Janeiro em 1992. Neste evento foi criada a Agenda 21, onde em seu princípio 7, verifica-se a importância da atitude cooperacionista, como conduta de proteção da natureza (MILARÉ, 2011, p. 102 - 111).

Destaca-se então, o referido princípio (MAZZUOLI, 2008, p. 1088):

\begin{abstract}
Princípio 7: Os Estados cooperarão espírito de parceria global para conservar, proteger e recuperar a saúde e integridade do ecossistema da Terra. Tendo em conta os diferentes contributos para a degradação ambiental global, os Estados têm responsabilidades comuns mas diferenciadas. Os países desenvolvidos reconhecem a responsabilidade que lhes cabe na procura do desenvolvimento sustentável a nível internacional, considerando as pressões exercidas pelas suas sociedades sobre o ambiente global e as tecnologias e os recursos financeiros que dispõe.
\end{abstract}

Miranda et al (2010, p. 25) ao analisar a cooperação oriunda do referido evento, afirma:

\begin{abstract}
A Cooperação prevista pela Declaração do Rio desnuda-se do aspecto econômico para enaltecer peculiaridades primitivas do trabalho conjunto de um grupo de países que devem sublimar a consciência da busca por um objetivo comum, qual seja, a preservação da biodiversidade e à proteção dos ecossistemas terrestres.
\end{abstract}

A essência do sentido da cooperação é algo primordial na garantia de um meio ambiente ecologicamente equilibrado, pois a atuação conjunta de vários protagonistas, que vão da esfera pública até a privada, consistindo em Estado, cidadãos e empresas, entre outros, agindo isoladamente, não abarcariam a complexidade das causas ambientais (BEAUD; BEAUD; BOUGUERRA, 1993, p. 552).

Para além dessa cooperação local, também há a cooperação entre os povos, princípio este de cunho global, estabelecida pelas relações internacionais que surgem do contexto de proteção ambiental mundial, pois bem se sabe que as agressões ambientais, nem sempre se limitam a territórios de um único país (MILARÉ, 2011, p. 1081). Pretenso a escala da referida cooperação, em vista da globalização, encontra-se o art. $4^{\circ}$, IX da Constituição brasileira, que elenca como princípio nas relações internacionais "a cooperação entre os povos para o progresso da humanidade” (BRASIL, 2010, p. 23). 
Assim, tendo em vista que as questões ambientais tornam-se relevantes pautas de discussões mundiais, surge então uma nova diretriz para tratativas internacionais, balizadas pela cooperação entre Estados.

O desenvolvimento de estratégias de proteção da natureza tem por meio efetivo o conhecimento dos referidos protagonistas, pois estando estes bem informados quanto aos impactos de condutas desvinculadas da sustentabilidade, podem se tornar agentes de proteção ambiental. Isto é alcançado através da implementação da atuação conjunta leia-se cooperação, pois em se tratando do meio ambiente natural, as consequências de um uso desregrado dos recursos naturais vão além das fronteiras geográficas, logo, deve-se fortalecer os laços de cooperação entre todos (MIRANDA; et. al, 2010, p. 27).

\section{A solidariedade como um valor presente e intergeracional}

Após breve comentário sobre o valor cooperativo, chega-se ao outro característico da sustentabilidade - a solidariedade. Esta vem ao encontro da responsabilidade com as gerações futuras, e, da mesma forma, com os que no presente se encontram, pois pensar num meio ambiente ecologicamente equilibrado é pensar num mundo de todos. Assim, atenta-se para a necessidade de banir condutas egoístas, referentes ao bem estar de alguns, em detrimento da qualidade de vida de outros. Nesse sentido, destacam-se as palavras de Togashi (2009, p. 299):

[...] A sustentabilidade tem em mira um mundo saudável agora e no futuro e a solidariedade entre as gerações e é um pressuposto, ao passo que o bemestar passa necessariamente pelo desenvolvimento social e é uma meta variável. Para a sustentabilidade é suficiente garantir que o estilo de vida atual se possa manter ainda por muitos anos ao nível mundial. Uma vez cumprido este critério, não é necessário empenhar-se por uma sustentabilidade ainda maior. [...].

Atitudes em prol da proteção da natureza, que garantam a qualidade de vida para todos, incitam laços solidários, pois como afirmado, cria-se uma ligação entre o "agora" e o "futuro". Exemplo prático do resultado da influência da solidariedade em condutas sociais pode-se destacar a economia solidária, que nas palavras de Franceschini et al (p. 4)., consiste num modelo que "busca outra qualidade de vida e outra forma de produzir e de consumir, defende que a eficiência dos empreendimentos não pode limitar-se aos 
benefícios materiais e aos processos produtivos, mas é definida também como eficiência social, em função da qualidade de vida de seus membros e de todo o ecossistema".

Atenta-se para a conservação de recursos naturais, responsáveis pelo suprimento das necessidades básicas dos seres humanos, e, da vida em geral, que está por vir. Desse contexto, verifica-se que o homem não vive sem ter um meio ambiente ecologicamente equilibrado, já a natureza, por si só, possui certa harmonia, mostrando ao homem, que sem ele pode existir, como em períodos passados, onde não existia a raça humana. Com isso, além de ser solidário com o seu semelhante da geração futura, o homem deve reforçar os laços de solidariedade com as causas ambientais, para a sua sobrevivência.

Para tanto, observa-se a necessidade de um desenvolvimento comprometido com a sustentabilidade, para aflorar e reforçar a solidariedade, tanto no presente momento, quanto adiante, ou seja, um desenvolvimento pautado pela harmonia entre progresso e preservação ambiental. Dessa forma, torna-se a consciência pelo sustentável como instrumento de intervenção no âmbito econômico, para assegurar a proteção do meio ambiente natural, preservando-o, mantendo o equilíbrio para se ter uma vida saudável inserida num meio ambiente da mesma forma, direito que é de todos. Destaca Campello (2008, p. 2393):

\begin{abstract}
Por outro lado, desenvolvimento sustentável é uma noção ética e solidária, sendo certo que os ideais de desenvolvimento e preservação não são incompatíveis. Pode-se conciliar perfeitamente a tutela do meio ambiente com a premente necessidade de progredir. Essa é a tese do desenvolvimento sustentável, que se ocupa dos excessos na produção de riquezas, destrutiva da própria base dessa produção, diante da observação de ineficácia do sistema e necessidade de um novo paradigma que pressupõe a reconstrução valorativa da sociedade.
\end{abstract}

Percebe-se também, no sentido da solidariedade, através da leitura do Art. 225 da atual Constituição brasileira, o que chama de princípio da solidariedade intergeracional, que diz: "Todos têm direito ao meio ambiente ecologicamente equilibrado, bem de uso comum do povo e essencial à sadia qualidade de vida, impondo-se ao Poder Público e à coletividade o dever de defendê-lo e preservá-lo para as presentes e futuras gerações" (BRASIL, 2010, p. 79). Verifica-se um anseio em preservar a natureza, cabendo ao Poder Público e à coletividade o dever de preservar e defender o meio ambiente natural, visando às necessidades atuais e futuras da 
[...] Embora valores como a solidariedade e a preocupação com a preservação das espécies sejam defendidos por governantes e cidadãos conscientes, ainda há muito que aprimorar para que os modelos de desenvolvimento das sociedades atuais tornem-se ecologicamente corretos e sustentáveis.

Assim, inúmeros valores devem ser estimulados, tanto quanto a cooperação e a solidariedade, uma vez que, as questões ambientais são fruto de uma sociedade que atualmente se mostra complexa.

\section{CONSIDERAÇÕES FINAIS}

Em se tratando de uma educação pautada nos anseios da natureza, se verifica que o saber ambiental incita nobres valores, quais sejam, a cooperação e solidariedade. Resumidamente, o primeiro refere-se à atuação conjunta em prol da colaboração mútua, pretendendo conciliar progresso e proteção da natureza, reavaliando certas condutas. Quanto ao segundo valor, é a essência para o comprometimento com a qualidade de vida das futuras gerações, voltando-se para uma postura responsável e preservacionista da natureza. Ao atender o escopo da sustentabilidade, ou seja, garantir um meio ambiente ecologicamente equilibrado, para as atuais e futuras gerações, se estimula os referidos valores.

A partir da construção da linguagem humana surge conjuntamente a noção de cooperação, pois é das atividades cooperativas que evolui as relações do ser na construção de família, comunidades e tribos. Aumenta-se cada vez mais a capacidade de cooperar, chegando ao atual contexto, mais especificamente, no âmbito econômico, onde mais do que nunca, emerge o valor da cooperação, tornando-se um princípio da economia para a preservação da natureza. Destaca-se também, do sentido de cooperar, os laços fortalecidos entre esfera pública e privada, em prol de um meio ambiente sadio, abarcando diversos protagonistas, como o Estado, cidadãos e empresas.

Tendo em vista a necessidade das gerações futuras, que também necessitarão de um meio ambiente ecologicamente equilibrado, emana a noção de solidariedade. $\mathrm{O}$ agora e o futuro fazem surgir à solidariedade entre gerações, onde a sustentabilidade se insere, para garantir qualidade de vida a todos. A possibilidade de existência das variadas formas de vida é inerente a disponibilidade de recursos naturais, sendo o vínculo solidário, tanto com o futuro da humanidade em si, quanto com as demandas 


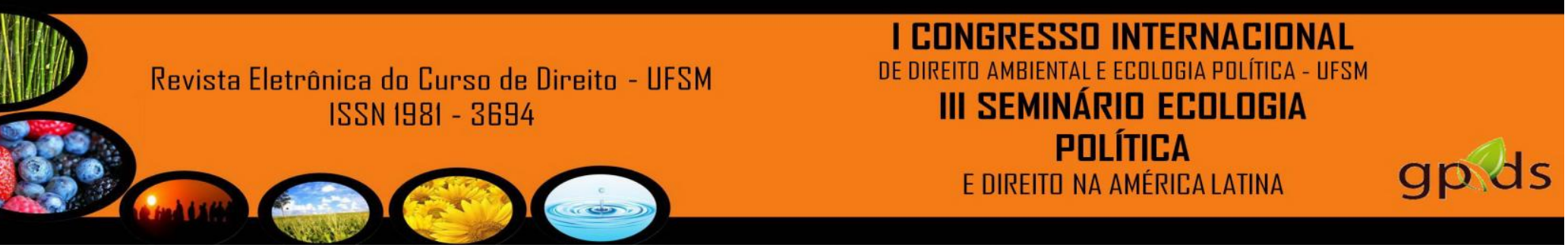

ambientais. Em sendo solidário com estas, garante-se a sobrevivência em decorrência da manutenção e preservação dos referidos recursos.

É dos citados valores em destaque, quando se fala em sustentabilidade, através da Educação Ambiental, que se vislumbra a possibilidade de uma mudança de paradigma social, alterado para uma consciência ecologicamente correta. Ambos os valores, explicitamente abordados neste trabalho, não excluem os demais oriundos da complexidade do saber ambiental. O pensamento que vai ao encontro dessas questões, não é tratado de forma isolada, fato que se percebe ao abordar solidariedade e cooperação, onde pensar em cada um remete ao outro, assim como a demais valores.

\section{REFERÊNCIAS BIBLIOGRÁFICAS}

BEAUD, Michel; BEAUD, Calliope; BOUGUERRA, Mohamed. Estado do ambiente no mundo. Lisboa, PO: Instituto Piaget, 1993.

BRASIL. Vade Mecum: Acadêmico de Direito. Anne Joyce Angher (org). 10 ed. São Paulo: Riddel, 2010.

BRUM, Andréia Barreto do Nascimento; HILLIG, Clayton. Repensando o consumismo: uma reflexão sobre a necessidade de um "consumo responsável". In: Revista Eletrônica em Gestão, Educação e Tecnologia Ambiental (REGETCET/UFSM). Santa Maria, v. 1, n. 1, pp. 115 - 128, 2010. Disponível em <http://cascavel.ufsm.br/revistas/ojs2.2.2/index.php/reget/article/viewFile/2300/1400> Acesso em 17 de mai de 2011.

CAPRA, Fritjof. A teia da vida. Cultrix: São Paulo, 1996.

CAMPELLO, Lívia Gaigher. O caminho da cooperação frente aos desafios impostos pela (in)sustentabilidade ambiental. In: Anais do XVII Congresso Nacional do CONPEDI. Florianópolis: Fundação Boiteux, 2008, pp. 2380 - 2400. Disponível em: <http://www.conpedi.org.br/manaus/arquivos/anais/brasilia/integra.pdf> Acesso em 1 de jun de 2011.

DERANI, Cristiane. Direito ambiental e econômico. 2 ed. São Paulo: Max Limonad, 2001.

MAZZUOLI, Valério de Oliveira. Coletânea de Direito Internacional, Constituição Federal. 6 ed. ver., ampl. e atual. São Paulo: Revista dos Tribunais, 2008.

MILARÉ, Édis. Direito do Ambiente: a gestão ambiental em foco: doutrina, jurisprudência, glossário. 7 ed. rev., atual. e reform. São Paulo: Revista dos Tribunais, 2011. 


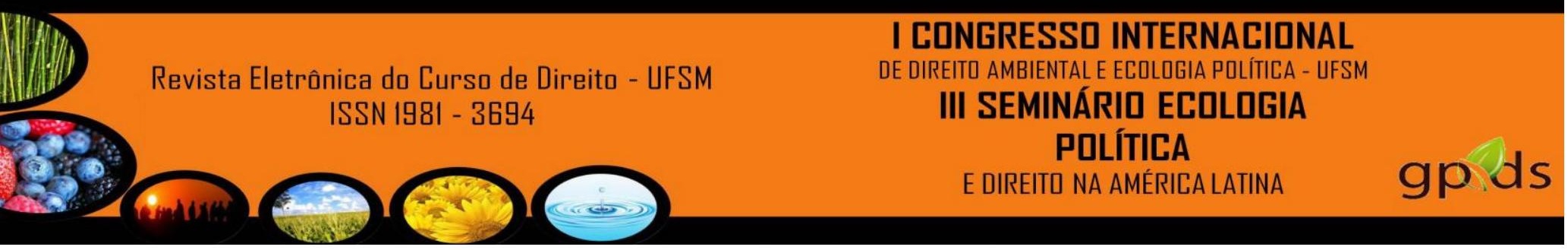

MIRANDA, José Eduardo et. al. Meio Ambiente e Cooperação: os valores cooperativos como pressuposto de sustentabilidade. Boletín de la Asociación Internacional de Derecho Cooperativo. Bilbao: Universidad de Deusto, n. 44, 2010. p 17 - 28. Disponível em: <http://www.fearp.usp.br/cooperativismo/observatorio/23.pdf> Acesso em 1 de jun de 2011.

SPAREMBERGER, Raquel Fabiana; FORTES, Vinícius Borges; PETRY, Diogo; FERRONATTO, Rafael Luiz. O Estado Constitucional Ecológico e o Estado Socioambiental de Direito como formas de assegurar o meio ambiente ecologicamente equilibrado. Disponível em: < http://www.diritto.it/pdf/27939.pdf> Acesso em: 1 de jul de 2011.

TOGASHI, Hiroshi. A sustentabilidade e o cosmopolitismo das relações de consumo na sociedade moderna: problematização de um paradoxo e perspectivas para o novo século. In: Voxjuris, ano 2, v. 2, pp. 293 - 319, 2009. Disponível em: <http://www.ugf.br/editora/pdf/voxjuris_2/artigo12.pdf> Acesso em 21 de mai de 2011. 